\title{
ÖÇB yaralanmalarına eşlik eden menisküs lezyonları
}

\author{
Meniscal lesions accompanying $A C L$ ruptures
}

\author{
Bertan Cengiz', Yusuf Mücahit Turan², Sinan Karaoğlu'1,3
}

${ }^{1}$ Acıbadem Kayseri Hastanesi, Ortopedi ve Travmatoloji Bölümü, Kayseri

${ }^{2}$ Acıbadem Kayseri Hastanesi, Fizik Tedavi ve Rehabilitasyon Birimi, Kayseri

${ }^{3}$ Acıbadem Üniversitesi Tıp Fakültesi, İstanbul

Ön çapraz bağ (ÖÇB) dizin ana stabilizatörlerinden olup, yokluğu durumunda eklem içi diğer yapıların hasar görme riskinde artışa sebep olabilir. ÖÇB yaralanması olan hastalarda menisküs yırtığı varlığının osteoartrit (OA) insidansında önemli bir artışa neden olduğu bildirilmiştir. ÖÇB yaralanmasına eşlik eden menisküs lezyonu oranlarının literatürde \%43'lere kadar olduğu bildirilmiştir. Lateral menisküs yırtıklarının akut ÖÇB yaralanmalarında, medial menisküs yırtıklarının ise kronik ÖÇB yırtıklarında daha fazla görüldüğü şeklinde klasik bir literatür bilgisi vardır. Ancak medial menisküs yırtıklarının akut ÖçB yaralanmasına daha fazla eşlik ettiğini bildiren çalışmalar da vardır. Yırtığın en sık görülen tipinin hem medial hem lateral menisküste longitudinal yırtık olarak gösterilmiştir. Inkomplet yırtıkların lateral menisküste daha fazla görüldüğü bildirilmiştir. Menisküs yırtığı lokalizasyonunun en sık olarak medial menisküsün arka bölümünde meniskokapsüler bileşkeye yakın bölgede olduğu bildirilmiştir. Ramp lezyonları medial menisküsün arka boynuzunun periferik yapışma yerinden olan yırtığıdır. Bu tespiti zor, klinik olarak önemi fazla olan lezyonun en önemli özelliği ÖÇB yırtıklarına sıklıkla eşlik etmesidir. Kronik ÖÇB rüptüründe akut yaralanmalara göre daha sık görülmektedir. Ramp lezyonu varlığında dizde eksternal rotasyonel instabilite ve anterior tibial translasyon anlamlı şekilde artar. Bu yırtıklarda tamir yönteminin daha iyi bir tedavi seçeneği olacağı bildirilmiştir. Safen nörovasküler demetle yakın komşuluğu sebebiyle tamir sırasında bu yapıları korunması önem teşkil eder. Yaş artışı, ilk yaralanma ile cerrahi arasındaki geçen süre, erkek cinsiyet ve vücut kitle indeksinin artışı yırtık riskini arttırır. Tedavisinde ÖÇB yaralanmasına eşlik eden menisküs yırtıklarının tamiri, standart bir prosedür haline gelmiştir.

Anahtar sözcükler: ön çapraz bağ; menisküs yırtığı; eşlik eden; ramp lezyonu
The anterior cruciate ligament (ACL) is one of the main stabilizers in the knee, and in its absence it may lead to an increased risk of damage to other intra-articular structures. The presence of concomitant meniscus tears in patients with ACL injuries has been reported to cause a significant increase in the incidence of osteoarthritis. The incidence of meniscus lesions accompanying ACL injuries have been reported to be up to $43 \%$ in the literature. There is a classical literature on lateral meniscus tears are more common in acute ACL injuries and medial meniscus tears in chronic ACL tears. However, there are also studies reporting that medial meniscus tears accompany acute ACL injury more. The most common type of tear has been shown to be a longitudinal tear in both the medial and lateral meniscus. It has been reported that incomplete tears are more common in the lateral meniscus. As the localization of the meniscus tear, it is reported that it is most frequently located in the posterior part of the medial meniscus, close to the meniscocapsular junction. Ramp lesion, defined as peripheral detachment lesion of posterior horn of medial meniscus. The most important feature of this difficult to detect and clinically important lesion is that it often accompanies ACL tears. It is more common in chronic $A C L$ ruptures than acute injuries. External rotational instability and anterior tibial translation significantly increase in the knee in the presence of a ramp lesion. It has been reported that repair will be a better treatment option in these tears. Because of its very close to the saphenous neurovascular bundle, it is important to preserve these structures during repair. The increase in age, the time from injury, the increase of male sex and body mass index increase the risk of meniscus tears. Repair of meniscus tears accompanying ACL injury in its treatment has become a standard procedure.

Key words: anterior cruciate ligament; meniscus tears; accompanying; ramp lesions

- Illetişim adresi: Prof. Dr. Sinan Karaoğlu, Acıbadem Kayseri Hastanesi, Ortopedi ve Travmatoloji Bölümü, Kayseri Tel: 0532 - 2873135 e-posta: sinankaraoglu@hotmail.com

- Geliștarihi: 9 Nisan $2020 \quad$ Kabul tarihi: 11 Mayıs 2020 
n çapraz bağ (ÖÇB) yaralanması, en sık spor yaralanmalarından birisi olup, Amerika Birleşik Devletlerinde 200.000/yıl ortalama yeni ÖÇB yaralanması vakası bildirilmektedir. ${ }^{[1]}$ ÖÇB dizin ana stabilizatörlerinden olup, yokluğu durumunda eklem içi diğer yapıların hasar görme riskinde artışa sebep olabilir. ${ }^{[2]}$ ÖÇB yaralanmasına eşlik eden eklem içi patolojiler de sıklıkla görülebilmektedir ki bunlardan en sık olanları menisküs yırtıkları ve kıkırdak lezyonlarıdır. Bu yaralanmalar ilk travma sonucu veya kronik instabil dizde görülen tekrarlayan makaslama ve rotasyonel kuvvetlerin sonucu olarak gelişebilmektedir. ${ }^{[3]}$ ÖÇB yetmezliği, menisküs yırtığı gelişme riskini ve yırtığın ciddiyetini artırmaktadır. ${ }^{[4,5]}$ Oysa ki ÖÇB rekonstrüksiyonu (ÖÇBR) stabilite ve fonksiyonun tekrar kazanılmasında yüksek oranda başarılı iken, osteoartrit (OA) oluşma insidansını belirgin olarak düşürdüğü gösterilememiştir. ${ }^{[6,7]}$ ÖÇB yaralanması sonrası 10 ile 15 yıllık bir periyotta, hastalarda OA düşündüren radyolojik bulgular ve fonksiyonel yetersizlik ortaya çıkabilir. ${ }^{[8]}$ Son zamanlarda, ÖÇB yaralanması olan hastalarda menisküs yırtığı varlığının $\mathrm{OA}$ insidansında önemli bir artışa neden olduğu bildirilmiştir. ${ }^{[9]}$

İsveç'ten yayınlanan yeni bir çalışmada ÖÇBR uygulanmış hastalarda, sadece ÖÇB yaralanması olanların ve eşlik eden menisküs veya kıkırdak hasarı olan hastaların 5 ve 10 yıllık takip sonuçları KOOS (Knee Injury and Osteoarthritis Outcome Score) skorlaması üzerinden değerlendirilmiştir ve bu skorun sadece ÖÇB yaralanması olanlarda, eşlik eden ek menisküs veya menisküs + kıkırdak yaralanması olanlara göre anlamIı olarak yüksek olduğunu bildirmişlerdir. ${ }^{[10]}$ Bundan yola çıkılarak ÖÇB rüptürüne eşlik eden diğer patolojiler gibi menisküs yırtıklarının erken tespiti ve tedavisi, ileride gelişebilecek OA gibi morbiditeyi ve dolayısıyla da tedavi maliyetlerinin artmasına sebep olacak rahatsızlıkların engellenebilmesi konusunda önem teşkil etmektedir. Yazımızda ÖÇB yırtıklarına eşlik eden menisküs lezyonlarından ve bu yaralanmaları etkileyen diğer faktörlerden, tedavisi ve nasıl önlenebileceği konularını gözden geçirdik.

\section{ÖÇB YARALANMASINA EŞLIK EDEN MENISKÜS YIRTIKLARI VE ÖZELLIKLERI}

ÖÇB yaralanmasına eşlik eden menisküs lezyonu oranlarının literatürde \%43'lere kadar olduğu bildirilmiştir. ${ }^{[11]}$ Lateral menisküs yırtıklarının akut ÖÇB yaralanmalarında, medial menisküs yırtıklarının ise kronik ÖÇB yırtıklarında daha fazla görüldüğü şeklinde klasik bir literatür bilgisi vardır. ${ }^{[12,13]}$ Ancak medial menisküs yırtıklarının akut ÖÇB yaralanmasına daha fazla eşlik ettiğini bildiren çalışmalar da vardır. ${ }^{[11,14]}$ Tandoğan ve ark.'nın yaptıkları, ÖÇBR uygulanmış olan 764 hastanın retrospektif analizinde bu hastaların \%72,8'inde bir veya daha fazla menisküs yırtığı tespit edilirken, bunların $\% 36,5^{\prime}$ inde medial menisküs, $\% 15,8$ 'inde lateral menisküs lezyonları görülmüş; \%20,4'ünde hem medial hem de lateral menisküs yırtıkları beraber görülmüştür. ${ }^{[15]}$ Farklı bir çalışmada ÖÇB cerrahisi sırasında görülen menisküs yırtıklarının \%38,97'sinin medial menisküsü, \%30,26'sının lateral menisküsü ilgilendirdiği bildirilmiştir. ${ }^{[16]}$ Yüksel ve ark. ÖÇBR sırasında hastaların \%81'inde eşlik eden en az bir menisküs lezyonu olduğu saptamışlar, medial menisküste anlamlı olmayacak şekilde, laterale göre daha fazla yırtık saptandığını bildirmişlerdir. [17]

Yırtığın en sık görülen tipi hem medial hem lateral menisküste longitudinal yırtık olarak gösterilmiştir. Radial yırtıklar ve parsiyel kalınlıktaki yırtıklar, lateral menisküste, mediale göre anlamlı olarak fazla oranda görülmüştür. ${ }^{[15]}$ Başka bir çalışmada yine en sık görülen yırtık tipinin longitudinal yırtık olduğunu; bunun medial menisküste $\% 71,1$ 'inin, lateralde $\% 66,1$ 'inin görüldüğünü bildirmişlerdir. İnkomplet yırtıkların \%18,9 oranında ve lateral menisküste daha fazla görüldüğü bildirilmiştir. Yırtık lokalizasyonu olarak en sık olarak medial menisküsün arka bölümünde meniskokapsüler bileşkeye yakın bölgede olduğu bildirilmiştir. ${ }^{[17]}$ Farklı bir çalışmada ise medial ve lateral menisküsün kova sapı yırtıklarının tam veya kısmi ÖÇB kopmalarında sıklığının anlamlı şekilde arttığını belirtilirken, medial menisküs posterior yırtıklarının daha az görüldüğü saptanmıştır. ${ }^{[18]}$

\section{Menisküs Ramp Lezyonları}

Illk olarak Strobel tarafından 1998'de tanımlanan, genelde ÖÇB yırtığıyla ilişkili olan, medial menisküs arka boynuzunun periferik yapışma yerinden olan yırtığıdır. ${ }^{[19]}$ Bu yırtığın patofizyolojisindeki en önemli kısım, yırtığın meniskokapsüler bileşke veya meniskotibial ligamentte meydana gelmesidir. Medial menisküsün arka boynuzunun anterior tibial translasyonu önlediği bilinmektedir. Dolayısıyla medial menisküsün bu kısmının bütünlügüu, eğer oluşmuşsa patolojinin tespiti ve tedavisi ciddi önem arz eder.[20,21]

Fakat tanısının konulması zor olup, özel bir fiziksel muayene testi yoktur; ayrıca menisküs lezyonlarının tanısında altın standart görüntüleme tekniği olan manyetik rezonansın (MR) ramp lezyonlarının tespitindeki duyarlılığı düşüktür. Hatta standart anteromedial ve anterolateral portallerden yapılan artroskopi ile de lezyonun tespiti çok zordur, çünkü yırtığın lokalizasyonu posteromedialdeki 'kör nokta' olup, ancak posteromedial portal kullanılarak tespit edilebilir. Standart skop yerine 70 derece skop 
ile görüntüleme yapılarak teşhisini koymak kolaylaşabilir. ${ }^{[22-24]}$ Bu tespiti zor, klinik olarak önemi fazla olan lezyonun en önemli özelliği ÖÇB yırtıklarına sıklıkla eşlik eder olmasıdır. Literatürde bütün ÖÇB rüptürlerinin \%9-17'sinde ramp lezyonunun eşlik ettiği bildirilmiştir. ${ }^{[22,25]}$

Risk faktörleri olarak yaş, cinsiyet ve yaralanma ile cerrahi arası geçen süre bildirilmiştir. Erkeklerde, kadınlara göre daha sık görülürken, 30 yaş altı hasta grubunda anlamlı olarak daha yüksek sıklıkta görülmektedir. Ek olarak yaralanma sonrası cerrahi yapılmadan geçen süre uzadıkça, lezyonun görülme sıklığı artar ki kronik ÖÇB rüptüründe akut yaralanmalara göre daha sık görülmektedir. ${ }^{[25]}$

Ramp lezyonlarının diz biyomekaniğindeki önemi büyüktür. Kadavra çalışmasında ÖÇB yırtığı olan dizde ramp lezyon benzeri bir lezyon oluşturmak için posteromedial meniskokapsüler ligament kesilerek diz biyomekanik olarak incelenmiş; eksternal rotasyonel instabilite ve anterior tibial translasyonun anlamlı şekilde arttığı bildirilmiştir. Ayrıca sadece ÖÇBR uygulandığında eksternal rotasyonel ve anterior instabilite giderilememiş, prosedüre meniskokapsüler onarım da eklenerek bu instabilite önlenebilmiştir. ${ }^{[26]}$

Ramp lezyonu tespit edildiğinde hangi tedavi yönteminin uygulanacağı konusunda fikir birliği yoktur. ${ }^{[27]}$ Kronik ÖÇB yaralanmasında ramp lezyonunun tamiri konusunda biraz daha tamir yönünde fikir birliği görülürken; akut yırtıklarda tedavi tartışmalıdır. Çünkü bazı yazarlar, ramp lezyonlarının, özellikle akut ÖÇB yırtıklarında, vasküler olarak iyi beslenen bir bölgede oluşmuş stabil bir yırtık olarak tanımlarlar. ${ }^{[25]}$ Bazı çalışmalar da ÖÇBR uygulanırken tespit edilen benzer longitudinal yırtıklarda, tamir edilmeyip kendi kendine iyileşmeye bırakılanların makul biçimde iyileştiklerini ve sonuçlarının iyi olduğu bildirilmiştir. ${ }^{[28,29]} \mathrm{Bu}$ çalışmalar konservatif tedaviyi önerirken, Ahn ve ark. diz fleksiyon-ekstansiyonu sırasında ramp lezyonundaki ayrışmış meniskokapsüler yapıların hipermobilitesinin, diğer periferal yırtıklara benzemediğini ve bu durumun iyileşmeye engel teşkil ettiğini bildirmişlerdir. ${ }^{[30]}$ Dolayısıyla bu yırtıklarda tamir yönteminin daha iyi bir tedavi seçeneği olacağını bildirmişlerdir.

Eğer cerrahi yöntem seçilirse yırtığı tamiri, bulunduğu anatomik bölge nedeniyle zorluklar içermektedir. Safen nörovasküler demetle yakın komşuluğu sebebiyle tamir sırasında bu yapıları korunması önem teşkil eder. Bu sebeple dıştan-içe tamir yöntemi seçilecekse çok dikkatli olunmalıdır ${ }^{[31]}$ Literatürde tamamı içeride ve içten dışa menisküs tamir tekniklerinin başarılı sonuçları sunulmuştur. ${ }^{[32]}$

\section{Etkileyen Faktörler}

\section{Yaş}

ÖÇB yaralanması olan hastalarda yaş faktörünün artması, eşlik eden menisküs yırtığı prevelansının artışıyla ilişkilidir. Brambillia ve ark.'nın çalışmasında artan yaşın bütün kıkırdak lezyonları ve medial menisküs yaralanmaları ile ilişkili olduğunu bildirmişlerdir, hatta artan her bir yaş için, eşlik eden lezyon görülme ihtimalinin 1,017 oranında artığını belirtmişlerdir. ${ }^{[16]}$ Yaş artışıyla lateral menisküs lezyonlarının oranının azaldığını, bunun yaşla birlikte aktivite düzeyinin ve travmanın enerjisinin azalması ile bağlantılı olduğunu bildirmişlerdir. ${ }^{[16]}$

Yaş ve ÖÇB yaralanmasına eşlik eden patolojiyi değerlendiren farklı çalışmalarda da yine yaş artışıyla ilişkili olarak medial menisküs lezyonları ve kıkırdak hasarı oranlarının arttığı bildirilmiştir. ${ }^{[2,33]}$ Yine yaş artışıyla beraber medial menisküsün kompleks yırtıklarının da arttığı gösterilmiştir. ${ }^{[15]}$

\section{ilk yaralanma ile cerrahi arasındaki süre}

Bu sürenin uzamasının kıkırdak hasarı ve medial menisküs yırtıklarının görülme insidansını artırdığını bildiren çalışmalar vardır. 12 aydan daha fazla gecikerek opere olan grupta yaralanma insidansı en yüksek bulunurken, $0-3$ ay arasında opere olanlarda bu oran en düşük düzeyde görülmüştür. Ancak bu sürenin uzamasının lateral menisküs lezyonlarının görülme sıklığını ve menisküs cerrahisi gerekliliğini arttırmadığı bildirilmiştir. ${ }^{[2]}$

Başka bir çalışmada ÖÇB yaralanmanın 6. haftasından daha erken cerrahi uygulanan hasta grubu 'akut', daha geç cerrahi uygulanmış olan grup ise 'kronik' olarak sınıflandırılmış ve kronik grupta medial menisküsün kompleks yırtıkların görülme oranının $(\% 37,2)$ akut gruptakine göre çok daha yüksek olduğu $(\% 7,7)$ bildirilmiştir. Bunun yanında akut grupta menisküs tamir oranları anlamlı olarak yüksekken (\%60,6'ya $\% 24,2)$, kronik grupta ise menisektomi oranları anlamlı olarak yüksektir (\%45,5'ye \%21,2). Yazarlar ÖÇB yaralanmalarında erken cerrahi müdahale kararı verilmesinin, menisküsün korunabilmesi açısından önemli olduğunu bildirmişlerdir. ${ }^{[34]}$

ÖÇB yaralanması ile cerrahi arasındaki gecikme nedeniyle menisküs yırtığı veya kıkırdak lezyonları gibi ek eklem içi patolojilerin görülme riskinin her ay için \%0,6 arttığı gösterilmiş, 12 . ayda artık riskin belirgin olarak arttığı bildirilmiştir. ${ }^{[16]}$ Medial menisküste yırtık riskinin belirgin olarak artışının yaralanma sonrası 6 . ay olduğunu bildiren farklı çalışmalar da mevcuttur. ${ }^{[35]}$

Yaralanma ile cerrahi süre arasındaki zamanın artışında ÖÇB yırtığına eşlik eden medial menisküs yırtık 
oranlarının arttığını bildiren çalışmalarda, akut dönem ile subkronik dönem arasında medial menisküs yırtığı oranlarında anlamlı fark görülmezken, kronik dönemde bu farkın belirgin şekilde arttığını bildirmişlerdir. Kronik dönemde $A C L$ yırtığına eşlik eden menisküs lezyonlarının oranını \%79,5'e kadar bildiren çalışmalar mevcuttur. ${ }^{[17]}$

\section{Cinsiyet}

Erkek ve kadınlar arasında oluşan lezyonların sıklıkları farklılık göstermektedir. Tam kat ÖÇB yırtıkları genelde erkeklerde daha fazla görülmektedir. ${ }^{[18]}$ Birçok çalışmada ÖÇB yaralanmasına eşlik eden menisküs yırtığı riskinin erkek cinsiyette daha fazla görüldüğü bildirilmiştir. ${ }^{[16,33]} \mathrm{Bu}$ durumun yüksek enerjili travmaların ve yüksek aktivite düzeyinin erkeklerde daha fazla olması ile ilişkili olduğu düşünülmektedir. Lateral menisküs yırtığının görülme riski kadınlarda azalır. ${ }^{[35]}$ Slauterbeck ve ark. da ÖÇB yaralanmasına eşlik eden menisküs lezyonlarının kadınlarda daha az sıklıkla görüldügünü bildirmişlerdir. ${ }^{[36]}$

\section{Yaralanma öncesi aktivite düzeyi}

Ralles ve ark. aktivite düzeyi düşük olan kişilerde ÖÇB yaralanmasına eşlik eden lezyonlardan medial menisküs yırtığının daha yüksek oranda görüldüğünü bildirmişlerdir. ${ }^{[2]}$ Tandoğan ve ark.'nın çalışmasında hastalarının spor aktivite düzeyi ile yaralanma paterni ve hasar gören yapıların arasında anlamlı ilişki bulunamamıştır. ${ }^{[15]}$ Oysa, farklı çalışmalarda normal düzeyde futbol oynayan kişilerle elit futbolcular karşılaştıııldığında, yaralanma tipinden bağımsız olarak yaralanma sonrası gonartroz riskinin üç kata kadar fazla görüldüğünü bildirmişlerdir. ${ }^{[37,38]}$ Bu durum göstermektedir ki yaralanma öncesi spor aktivite düzeyi ile yaralanma paterni arasında ilişki yoktur ancak aktivite düzeyi yüksek olan elit futbolcular gibi hasta gruplarında yaralanmanın uzun dönem sekelleri daha şiddetli olmaktadır. ${ }^{[15]}$

\section{Vücut kitle indeksi (VKi)}

Mekanik anlamda yüklenmenin daha fazla olması nedeniyle ÖÇB yaralanması olan ve VKi yüksek olan hastalarda, eşlik eden menisküs lezyonlarının ve ek eklem içi patolojilerin görülme riski daha yüksektir. ${ }^{[16,39]}$ Bu hastalarda OA ilerleme insidansının yüksek olması nedeniyle erken zamanda cerrahinin gerçekleştirilmesi yönünde hastalara tavsiyede bulunulması daha doğru bir yaklaşım olacaktır.

\section{Tedavi ve Sonuçları}

Son iki dekatta ÖÇB yaralanmasına eşlik eden menisküs yırtıklarının tamiri, standart bir prosedür haline gelmiştir. ${ }^{[0,41]}$ Çalışmalar ÖÇBR yapılırken uygulanan menisküs tamirinin sonuçlarının, sadece menisküs yırtığı olup tamir uygulanan hastalara göre daha iyi olduğunu bildirmektedirler. ${ }^{[42]}$ Yapılan çalışmalarda ACLR ile birlikte menisküs onarımının kısa dönem sonuçlarının, hastaların ilk 6 ay boyunca biraz daha kötü subjektif fonksiyona sahip olabileceğini göstermektedir. ${ }^{[43]}$ Fakat uzun vadede, menisküs korunduğu zaman, ortaya çıkan artrometrik ölçümler ve osteoartrit bulguları açısından çok daha iyi sonuçlar göstermektedir. ${ }^{[4]}$

Yeni yapılmış olan bir çalışmada, ÖÇB rekonstrüksiyonu ile eş zamanlı uygulanan menisküs tamiri prosedürünü takiben, operasyon sonrası 6 . ayda izokinetik kuvvet kaybı görülmediği bildirilmiştir. Bu çalışmada menisküs yırtığının lokalizasyonuna göre izokinetik kuvvet değerlendirilmesinde medial menisküs onarımının, laterale göre daha iyi sonuçlar gösterdiği bildirilmiştir. ${ }^{[45]}$

Cerrahi tamir tekniği olarak yırtığın lokalizasyonu ve şekli önemlidir. Klasik teknikler olan diştan-içe, içten-dışa ve tamamı içeride tamir teknikleri ile menisküs onarımı sağlanabilir. Ancak özellikle ramp lezyonlarında safen nörovasküler demet ile yakın ilişkisi nedeniyle sütürleri geçirme ve düğümleri bağlama sırasında bu yapıların zarar görme riski yüksektir. ${ }^{[31]}$ Bu nedenle bu lezyonların tedavisi genelde tamamı içeride tamir teknikleriyle uygulanmaktadır. Posteromedial portal ve buna yakın aksesuar ikinci bir portal yardımıyla sütür geçirici aletlerle lezyonun her iki tarafından sütürler geçirilerek düğümlenmesi suretiyle yapılan tamir sonuçları gayet yüz güldürücüdür. ${ }^{[28,30]}$ Bunun yanında; FastFix ve Ultra FastFix 360 gibi tamamı içeride menisküs tamir sistemleri (Smith and Nephew) kullanılarak yapılan çalışmalarda da, yapılan tamirlerin gayet yüksek başarı yüzdesi ve düşük komplikasyon oranlarına sahip olduğu bildirilmiştir. ${ }^{[32,46]}$

Artık çok iyi anlaşılmıştır ki, ÖÇBR sırasında, mümkün olduğunca menisküsün korunması ciddi önem teşkil etmektedir. Bu tedavi yöntemi diz stabilitesini artırarak, yeniden operasyon riskini azaltır; klinik sonuçlarda düzelme sağlarken, uzun vadede OA gelişme riskini de azaltmaktadır. ${ }^{[42,47]}$

\section{KAYNAKLAR}

1. Paterno MV, Rauh MJ, Schmitt LC, Ford KR, Hewett TE. Incidence of contralateral and ipsilateral anterior cruciate ligament $(A C L)$ injury after primary $A C L$ reconstruction and return to sport. Clin J Sport Med 2012;22(2):116-21. Crossref

2. Ralles S, Agel J, Obermeier M, Tompkins M. Incidence of Secondary Intra-articular Injuries With Time to Anterior Cruciate Ligament Reconstruction. Am J Sports Med 2015;43(6):1373-9. Crossref 
3. Michalitsis S, Vlychou M, Malizos KN, Thriskos $P$, Hantes ME. Meniscal and articular cartilage lesions in the anterior cruciate ligament-deficient knee: correlation between time from injury and knee scores. Knee Surg Sports Traumatol Arthrosc 2015;23(1):232-9. Crossref

4. Mehl J, Otto A, Baldino JB, Achtnich A, Akoto R, Imhoff AB, Sven Scheffler, Petersen W. The ACL-deficient knee and the prevalence of meniscus and cartilage lesions: a systematic review and meta-analysis (CRD42017076897). Arch Orthop Trauma Surg 2019;139(6):819-41. Crossref

5. Hagmeijer MH, Hevesi M, Desai VS, Camp CL, Hewett TE, Stuart MJ, Saris DBF, Krych AJ,§. Secondary Meniscal Tears in Patients with Anterior Cruciate Ligament Injury: Relationship Among Operative Management, Osteoarthritis, and Arthroplasty at 18-Year Mean Follow-up. Am J Sports Med 2019;47(7):1583-90. Crossref

6. Church S, Keating JF. Reconstruction of the anterior cruciate ligament: timing of surgery and the incidence of meniscal tears and degenerative change. J Bone Joint Surg Br 2005;87$B(12): 1639-42$. Crossref

7. Beynnon BD, Johnson RJ, Abate JA, Fleming BC, Nichols CE. Treatment of anterior cruciate ligament injuries, part I. Am J Sports Med 2005;33(10):1579-602. Crossref

8. Lohmander LS, Englund PM, Dahl LL, Roos EM. The longterm consequence of anterior cruciate ligament and meniscus injuries: osteoarthritis. Am J Sports Med 2007;35(10):175669. Crossref

9. Øiestad BE, Engebretsen L, Storheim K, Risberg MA. Knee osteoarthritis after anterior cruciate ligament injury: a systematic review. Am J Sports Med 2009;37(7):1434-43. Crossref

10. Balasingam S, Sernert N, Magnusson H, Kartus J. Patients with Concomitant Intra-articular Lesions at Index Surgery Deteriorate in Their Knee Injury and Osteoarthritis Outcome Score in the Long Term More Than Patients With Isolated Anterior Cruciate Ligament Rupture: A Study From the Swedish National Anterior Cruciate Ligament Register. Arthroscopy 2018;34(5):1520-9. Crossref

11. Keene GC, Bickerstaff D, Rae PJ, Paterson RS. The natural history of meniscal tears in anterior cruciate ligament insufficiency. Am J Sports Med 1993;21(5):672-9. Crossref

12. Cipolla M, Scala A, Gianni E, Puddu G. Different patterns of meniscal tears in acute anterior cruciate ligament $(A C L)$ ruptures and in chronic ACL-deficient knees. Classification, staging and timing of treatment. Knee Surg Sports Traumatol Arthrosc 1995;3(3):130-4. Crossref

13. Smith JP 3rd, Barrett GR. Medial and lateral meniscal tear patterns in anterior cruciate ligament-deficient knees. A prospective analysis of 575 tears. Am J Sports Med 2001;29(4):415-9. Crossref

14. Paletta GA Jr, Levine DS, O'Brien SJ, Wickiewicz TL, Warren RF. Patterns of meniscal injury associated with acute anterior cruciate ligament injury in skiers. Am J Sports Med 1992;20(5):542-7. Crossref

15. Tandogan RN, Taşer O, Kayaalp A, Taşkıran E, Pınar H, Alparslan B, Alturfan A. Analysis of meniscal and chondral lesions accompanying anterior cruciate ligament tears: relationship with age, time from injury, and level of sport. Knee Surg Sports Traumatol Arthrosc 2004;12(4):262-70. Crossref

16. Brambilla L, Pulici L, Carimati G, Quaglia A, Prospero E, Bait C, Morenghi E, Portinaro N, Denti M, Volpi P. Prevalence of Associated Lesions in Anterior Cruciate Ligament Reconstruction: Correlation with Surgical Timing and with Patient Age, Sex, and Body Mass Index. Am J Sports Med 2015;43(12):2966-73. Crossref
17. Yüksel HY, Erkan S, Uzun M. The evaluation of intraarticular lesions accompanying $\mathrm{ACL}$ ruptures in military personnel who elected not to restrict their daily activities: the effect of age and time from injury. Knee Surg Sports Traumatol Arthrosc 2006;14(11):1139-47. Crossref

18. Unay K, Akcal MA, Gokcen B, Akan K, Esenkaya I, Poyanlı O. The relationship between intra-articular meniscal, chondral, and $\mathrm{ACL}$ lesions: finding from 1,774 knee arthroscopy patients and evaluation by gender. Eur J Orthop Surg Traumatol 2014;24(7):1255-62. Crossref

19. Strobel MJ. Manual of Arthroscopic Surgery. Berlin, Heidelberg: Springer-Verlag; 2002. Crossref

20. Lorbach O, Kieb M, Herbort M, Weyers I, Raschke M, Engelhardt $M$. The influence of the medial meniscus in different conditions on anterior tibial translation in the anterior cruciate deficient knee. Int Orthop 2015;39(4):6817. Crossref

21. Peltier A, Lording TD, Lustig S, Servien E, Maubisson L, Neyret P. Posteromedial meniscal tears may be missed during anterior cruciate ligament reconstruction. Arthroscopy 2015;31(4):691-8. Crossref

22. Bollen SR. Posteromedial meniscocapsular injury associated with rupture of the anterior cruciate ligament: a previously unrecognised association. J Bone Joint Surg Br 2010;92$B(2): 222-3$. Crossref

23. Chahla J, Dean CS, Moatshe G, Mitchell JJ, Cram TR, Yacuzzi C, LaPrade RF,. Meniscal Ramp Lesions: Anatomy, Incidence, Diagnosis, and Treatment. Orthop J Sports Med 2016;4(7):2325967116657815. Crossref

24. Gülenç B, Kemah B, Yalçın S, Sayar Ş, Korkmaz O, Erdil M. Surgical Treatment of Meniscal RAMP Lesion. J Knee Surg 2020;33(3):255-9. Crossref

25. Liu X, Feng $\mathrm{H}$, Zhang $\mathrm{H}$, Hong L, Wang XS, Zhang J. Arthroscopic prevalence of ramp lesion in 868 patients with anterior cruciate ligament injury. Am J Sports Med 2011;39(4):832-7. Crossref

26. Stephen JM, Halewood C, Kittl C, Bollen SR, Williams A, Amis AA. Posteromedial Meniscocapsular Lesions Increase Tibiofemoral Joint Laxity with Anterior Cruciate Ligament Deficiency, and Their Repair Reduces Laxity. Am J Sports Med 2016;44(2):400-8. Crossref

27. Shoemaker SC, Markolf KL. The role of the meniscus in the anterior-posterior stability of the loaded anterior cruciatedeficient knee. Effects of partial versus total excision. J Bone Joint Surg Am 1986;68(1):71-9. Crossref

28. Duchman KR, Westermann RW, Spindler KP, Reinke EK, Huston LJ, Amendola A, MOON Knee Group, Wolf BR,. The Fate of Meniscus Tears Left in Situ at the Time of Anterior Cruciate Ligament Reconstruction: A 6-Year Follow-up Study from the MOON Cohort. Am J Sports Med 2015;43(11):2688-95. Crossref

29. Shelbourne KD, Rask BP. The sequelae of salvaged nondegenerative peripheral vertical medial meniscus tears with anterior cruciate ligament reconstruction. Arthroscopy 2001;17(3):270-4. Crossref

30. Ahn JH, Wang JH, Yoo JC. Arthroscopic all-inside suture repair of medial meniscus lesion in anterior cruciate ligament-deficient knees: results of second-look arthroscopies in 39 cases. Arthroscopy 2004;20(9):936-45. Crossref

31. Rodeo SA. Arthroscopic meniscal repair with use of the outside-in technique. Instr Course Lect 2000;49:195-206.

32. Li WP, Chen Z, Song B, Yang R, Tan W. The FasT-Fix Repair Technique for Ramp Lesion of the Medial Meniscus. Knee Surg Relat Res 2015;27(1):56-60. Crossref 
33. Sri-Ram K, Salmon LJ, Pinczewski LA, Roe JP. The incidence of secondary pathology after anterior cruciate ligament rupture in 5086 patients requiring ligament reconstruction. Bone Joint J 2013;95-B(1):59-64. Crossref

34. Burnett RA, Westermann R, Duchman K, Amendola N, Hettrich C, Wolf B, Glass N, Bollier M. Intra-Articular Pathology Associated with Acute and Chronic Anterior Cruciate Ligament Reconstruction. lowa Orthop J 2019;39(1):101-6. https://europepmc.org/article/pmc/ pmc6604549

35. Chhadia AM, Inacio MC, Maletis GB, Csintalan RP, Davis $\mathrm{BR}$, Funahashi TT. Are meniscus and cartilage injuries related to time to anterior cruciate ligament reconstruction? Am J Sports Med 2011;39(9):1894-9. Crossref

36. Slauterbeck JR, Kousa P, Clifton BC, Naud S, Tourville TW, Johnson RJ, Beynnon BD. Geographic mapping of meniscus and cartilage lesions associated with anterior cruciate ligament injuries. J Bone Joint Surg Am 2009;91(9):2094103. Crossref

37. Larsen E, Jensen PK, Jensen PR. Long-term outcome of knee and ankle injuries in elite football. Scand J Med Sci Sports 1999;9(5):285-9. Crossref

38. Roos $\mathrm{H}$, Lindberg $\mathrm{H}$, Gärdsell $\mathrm{P}$, Lohmander LS, Wingstrand $\mathrm{H}$. The prevalence of gonarthrosis and its relation to meniscectomy in former soccer players. Am J Sports Med 1994;22(2):219-22. Crossref

39. Wills AK, Black S, Cooper R, Coppack RJ, Hardy R, Martin KR, Cooper C, Kuh D,. Life course body mass index and risk of knee osteoarthritis at the age of 53 years: evidence from the 1946 British birth cohort study. Ann Rheum Dis 2012;71(5):655-60. Crossref

40. Abram SGF, Price AJ, Judge A, Beard DJ. Anterior cruciate ligament $(A C L)$ reconstruction and meniscal repair rates have both increased in the past 20 years in England: hospital statistics from 1997 to 2017. Br J Sports Med 2020;54(5):286-91. Crossref
41. Westermann RW, Wright RW, Spindler KP, Huston LJ, MOON Knee Group, Wolf BR. Meniscal repair with concurrent anterior cruciate ligament reconstruction: operative success and patient outcomes at 6-year follow-up. Am J Sports Med 2014;42(9):2184-92. Crossref

42. Wasserstein D, Dwyer T, Gandhi R, Austin PC, Mahomed $\mathrm{N}$, Ogilvie-Harris D. A matched-cohort population study of reoperation after meniscal repair with and without concomitant anterior cruciate ligament reconstruction. Am J Sports Med 2013;41(2):349-55. Crossref

43. Svantesson E, Cristiani R, Hamrin Senorski E, Forssblad M, Samuelsson K, Stalman A. Meniscal repair results in inferior short-term outcomes compared with meniscal resection: a cohort study of 6398 patients with primary anterior cruciate ligament reconstruction. Knee Surg Sports Traumatol Arthrosc 2018;26(8):2251-8. Crossref

44. Shelbourne KD, Gray T. Results of anterior cruciate ligament reconstruction based on meniscus and articular cartilage status at the time of surgery. Five- to fifteen-year evaluations. Am J Sports Med 2000;28(4):446-52. Crossref

45. Wenning M, Heitner AH, Mauch M, Gehring D, Ramsenthaler C, Paul J. The effect of meniscal repair on strength deficits 6 months after ACL reconstruction [published online ahead of print, 2020 Jan 29]. Arch Orthop Trauma Surg 2020. Crossref

46. Heilpern G, Stephen J, Ball S, Amis A, Williams A. It is safe and effective to use all inside meniscal repair devices for posteromedial meniscal 'ramp' lesions. Knee Surg Sports Traumatol Arthrosc 2018;26(8):2310-6. Crossref

47. LaPrade CM, Dornan GJ, Granan LP, LaPrade RF, Engebretsen L. Outcomes After Anterior Cruciate Ligament Reconstruction Using the Norwegian Knee Ligament Registry of 4691 Patients:How Does Meniscal Repair or Resection Affect Short-term Outcomes? Am J Sports Med 2015;43(7):1591-7. Crossref 